\title{
Associated Anomalies among Infants with Oral Clefts at Birth and during a 1 year Follow-up
}

\author{
Monica Rittler ${ }^{1}$, Viviana Cosentino ${ }^{2}$, Jorge S López-Camelo ${ }^{2,3}$, Jeffrey C Murray ${ }^{4}$, George \\ Wehby $^{5}$, and Eduardo E Castilla ${ }^{2,6}$ \\ ${ }^{1}$ Latin-American Collaborative Study of Congenital Malformations, WHO Collaborating Centre for \\ the Prevention of Birth Defects (ECLAMC) at Hospital Materno Infantil Ramón Sardá, Buenos \\ Aires, Argentina \\ ²ECLAMC at CEMIC (Centro de Educación Médica e Investigación Clínica), Buenos Aires, \\ Argentina \\ ${ }^{3}$ ECLAMC at IMBICE (Instituto Multidisciplinario de Biologia Celular), La Plata, Argentina \\ ${ }^{4}$ Department of Pediatrics, University of lowa, lowa City, IA USA \\ ${ }^{5}$ College of Public Health, University of lowa, lowa City, IA USA \\ 6INAGEMP (Instituto Nacional de Genética Médica Populacional) at Laboratório de Epidemiologia \\ de Malformações Congênitas, Instituto Oswaldo Cruz, Fundação Oswaldo Cruz, Rio de Janeiro, \\ Brazil
}

\section{Abstract}

Reports of birth defects rates may focus on defects observed in the newborn period or include defects diagnosed at older ages. However, little information is available on the rates of additional anomalies detected after birth or on the ages at which such anomalies are diagnosed. The aims of this work were to describe the initial diagnoses of oral clefts, isolated or associated with other defects, in newborn infants ascertained in hospitals of the ECLAMC network, and diagnostic changes that occurred due to detection of additional defects during a one-year follow-up period. Seven hundred ten liveborn infants with cleft lip only (CLO), cleft lip with cleft palate (CLP), or cleft palate (CP) were ascertained between 2003 and 2005. Prevalence estimates of isolated and associated clefts, diagnoses in infants with associated clefts, and the percentage of isolated clefts that were reclassified as associated were established. Birth prevalence estimates (per 1,000) were as follows: Total: 1.7; CLP: 0.94 (ASO=23.5\%); CP: 0.46 (ASO=42.3\%); CLO: 0.28 (ASO $=7.6 \%$ ). Initial diagnoses in infants with associated clefts included 38 infants with chromosomal abnormalities, 33 with non-chromosomal syndromes, 16 with malformation sequences, and 98 with multiple anomalies of unknown etiology. Seven percent of newborns initially classified as isolated were later reclassified as associated. Ten infants without associated defects or clinically suspected syndromes were diagnosed as syndromic only through laboratory findings or family history, illustrating the difference between the terms associated vs. isolated, which refers to presence or absence of associated anomalies, and syndromic vs. non-syndromic, which refers to etiology.

\section{Keywords}

oral clefts; isolated; associated; follow-up; syndromic 


\section{INTRODUCTION}

Oral clefts as isolated defects, associated with other anomalies or as part of syndromes, are among the most frequent birth defects [Owens et al., 1985]. The types and rates of associated defects vary, depending on the age of the infant, the length of follow-up, and other factors. Such variations across time imply that changes in diagnoses, as well as in prognosis and recurrence risks, occur as the child gets older and more associated defects are recognized.

A number of birth defects surveillance systems report birth defect rates in newborn infants only, while others also include defects detected in older children [ICBDSR, 2009; Bower et al., 2010], sometimes with variable lengths of follow-up [Milerad et al., 1997; Shaw et al., 2004], but few of these have focused on the prevalence of additional anomalies recognized at different ages or on the ages at which those additional anomalies were diagnosed [Tan et al., 2009; Bower et al., 2010].

ECLAMC (Latin American Collaborative Study of Congenital Malformations) [Castilla and Orioli, 2004] is a clinical epidemiological program, operating in South America since 1967 that carries out research on birth defects. Between 2003 and 2005, 48 selected maternity hospitals in the ECLAMC network participated in a special intervention trial that included regular pediatric visits until one year of age, aimed at evaluating the long-term outcome of children with oral clefts [Wehby et al., 2006].

The aims of this work were to describe the initial diagnoses of oral clefts (isolated or associated with other defects) in newborn infants ascertained in hospitals of the ECLAMC network, and the diagnostic changes that occurred due to detection of additional defects during a one-year follow-up period.

\section{MATERIAL AND METHODS}

In the ECLAMC network, newborn infants with birth defects are ascertained by specially trained pediatricians, following a common methodology, between birth and hospital discharge. All information concerning these infants and included in the medical records is regularly reported by pediatricians to the coordinating group for classification and registration. Although procedures require that these pediatricians review and update the clinical information after their initial report, this does not routinely occur.

Within the framework of a special intervention study, infants with clefts ascertained at birth in 48 maternity hospitals from 7 countries of the ECLAMC network (Argentina, Bolivia, Brazil, Chile, Colombia, Ecuador, and Venezuela) were followed by their pediatricians until one year of age with regular physical examinations. Further relevant data were added to the medical history taken at birth and submitted to the coordinating group.

From a total of 10,371 malformed newborns ascertained among 422,240 livebirths between January 2003 and December 2005, all infants with oral clefts, except those with bifid uvula, with clefts of the lip that were medial, oblique atypical, or congenitally "healed", with submucous cleft palate, or with birth weight $<500 \mathrm{~g}$, were included in the study. The clefts were classified as cleft lip with cleft palate (CLP), cleft lip only (CLO), or cleft palate (CP).

Diagnoses and classification of the infants with clefts were based on the information provided by the pediatricians in the submitted medical records, and on its further evaluation by dysmorphologists and geneticists of the coordinating group, with the aid of available photographs, and any other relevant information submitted by the attending pediatricians 
during the one-year follow-up. As part of the study, all infants regardless of their clinical findings had chromosome analyses performed. Fluorescence in situ hybridization (FISH) testing for 22q11.2 deletion is not regularly performed at the participating hospitals, and was not required as part of this study.

Other molecular analyses are also not performed at the hospitals nor were they part of this work. However, blood samples for DNA analysis were taken from all infants with clefts and their parents and centralized at a number of laboratories participating in the study for future research. Preliminary results were obtained from a related project focusing on three genetic conditions known to be associated with clefts (22q11.2 deletion, van der Woude syndrome, and Kallmann syndrome). Of the total newborns with clefts included in our study, a subsample of 79 unselected infants with isolated clefts also participated in that project and had molecular analyses performed for these three conditions.

Based on the initial information provided by the reporting pediatricians, clefts were initially classified as isolated or associated, depending on the presence of other major unrelated defects detected and reported between birth and hospital discharge. Major defects were defined as those requiring medical or surgical intervention, or of substantial cosmetic importance, as well as clinically recognizable or suspected syndromes. Infants in whom an oral cleft without other major anomalies was diagnosed were classified as having an isolated cleft, while those with additional major defects were classified as having an associated cleft.

All defects were coded according to a specific descriptive system previously described for oral clefts [Castilla and Orioli, 2009], as well as for other anomaly types [Castilla and Orioli, 2004]. Prevalence estimates and proportions of isolated and associated cases were obtained for each type of cleft. Mortality rates were established for the isolated group by type of cleft.

Infants with associated clefts were assigned to one of 4 diagnostic groups: chromosomal abnormalities, other clinically recognized or suspected syndromes, malformation complexes/ sequences, and multiple congenital anomalies of unknown cause (MCA) (clefts with other major unrelated defects without an identified etiology).

Considering the inconsistent definition of Pierre Robin sequence applied in clinical practice and consequently its possible over- or under-reporting, Pierre Robin was classified as isolated CP.

During the one year follow-up period, additional birth defects that were detected and any other relevant information submitted by the attending pediatricians were added to the initial diagnoses, thus leading to the reassignment of a number of infants with isolated clefts to the associated group. The reports of all infants were re-evaluated at the end of the one-year period.

The study was reviewed and approved by the ethics committee of each participating hospital, and signed parental consent was obtained for the infants with clefts included in the study.

\section{RESULTS}

A total of 710 liveborn infants with oral clefts were included in the study (total birth prevalence $=1.7 / 1,000$ livebirths) (Table I). CLP was the most frequent type (birth prevalence $=0.94 / 1,000 ; 55.6 \%)$, followed by $\mathrm{CP}($ birth prevalence $=0.46 / 1,000 ; 27.6 \%)$, and by CLO (birth prevalence $=0.28 / 1,000 ; 16.8 \%$ ). Most $(73.9 \%$ ) infants were initially classified as having an isolated cleft, with the remainder (26.1\%) classified as having an 
associated cleft. Nearly half of the newborns with CP (42.3\%), 23.5\% of those with CLP, and $7.6 \%$ of those with CLO had associated anomalies.

\section{Mortality}

Among 525 newborns with isolated clefts, 14 (2.6\%) died. All deaths occurred during the first month of life, except one that occurred at 5 months, with no further available data. Nine of the 14 who died were preterm with birth weights between 500 and $1700 \mathrm{~g}$, and the main cause of death was related to prematurity. Among the remaining infants, three died of aspiration and pneumonia and one died after developing a chylothorax. No autopsies were performed. Five of the 14 infants who died had a CLO (4.5\% of all infants with isolated CLO), the remaining 9 who died had a CLP ( $3 \%$ of all infants with isolated CLP), while no deaths occurred among infants with an isolated $\mathrm{CP}$.

Among 185 newborns with associated clefts, 87 (47\%) died, and all deaths except one occurred during the first month of life. These infants all had severe associated anomalies or syndromes.

\section{Diagnoses of associated cases}

Cytogenetic testing was performed in 281 infants with clefts initially diagnosed as isolated and in 108 infants with associated clefts (total results= 55\%). The reasons for not obtaining chromosome results in the rest of the sample were mainly early infant death and failed cultures.

In Table II, the initial diagnoses of 185 infants with associated clefts are shown. CLP was the most frequent cleft type in infants with chromosomal abnormalities, while CP predominated in non-chromosomal syndromes, among which conditions with arthogryposis were most commonly observed.

Four malformation sequences or complexes without other unrelated defects were diagnosed; the most frequent was the branchial arch malformation complex in 7 infants (4 with CLP and 3 with $\mathrm{CP}$ ). Microtia and preauricular tags were the main associated defects.

The group of MCA was the largest, with 98 infants. However, since chromosome results were not obtained in almost half of the cases, the inclusion of infants with undetected chromosome anomalies in this group cannot be ruled out.

Congenital heart defects (CHDs) were by far the defects most frequently associated with clefts in infants in the MCA group (31/98=31.6\%). However, the proportion of CHDs associated with clefts among the entire sample of 710 infants (7.7\%; 95\%CI: 5.4-9.9) did not differ from the proportion of CHDs associated with other non-cleft anomalies (6.2\%; 95\%CI: 5.7-6.7), ascertained at the same hospitals and during the same period (data not shown).

Other associated anomalies in infants with MCA were limb deficiencies (7), anal atresia (6), hydronephrosis (5), and others with less than 3 cases each. The numbers of all of them were too small to estimate association rates.

\section{Follow-up}

During the one-year follow-up, 38 infant initially diagnosed as having an isolated cleft were reassigned to the associated group (7.2\%), raising the proportion of associated clefts from 26.1 to $31.4 \%$. 
Twenty-four of the 38 infants were reassigned because of the detection of a major defect. In 8 of the 38 infants, the reassignment was based on a clinical re-evaluation of minor anomalies. The remaining 6 had been incorrectly assigned by the coordinating group and were appropriately reclassified at the end of the one-year period (Table III).

In most of the 24 infants with additionally detected major anomalies, the detection occurred within the first month of life; the latest were 2 cases of anal stenosis diagnosed at 1 year of age. CHDs were the most frequent anomalies detected at older ages, followed by urinary system and brain anomalies.

Syndromes were identified in the 8 infants whose reassignment was based on a clinical reevaluation of minor anomalies: 6 had a chromosomal abnormality, one had RubinsteinTaybi syndrome, and one had Cornelia de Lange syndrome. All 8 were diagnosed within the first week of life, although after having been initially assigned to the isolated clefts group (Table IV).

In ten infants with isolated clefts, a syndrome was diagnosed after consideration of laboratory findings or family history information. Since these infants had no other major defects nor clinically recognizable syndromes, they were not part of the 38 infants reassigned to the associated clefts group, but remained classified as isolated during the entire study (Table V).

As expected, none of the infants initially classified as having an associated cleft had to be reclassified as isolated during the follow-up period.

\section{Infants without follow-up}

Of the 511 infants with isolated clefts who were discharged alive, $41(8 \%)$ were lost to follow-up during the first month and 113 during the rest of the first year (22.1\%) (total loss to follow-up: $30.1 \%$ ).

Of the 98 infants with associated clefts who were discharged alive, 9 were lost to follow-up during the first month and 39 during the rest of the first year (total loss to follow-up: 49\%). All infants lost to follow-up remained classified according to their latest diagnoses.

\section{DISCUSSION}

In the present study we showed that almost $10 \%$ of infants with an apparently isolated oral cleft in fact had other major defects that were detected during a one-year follow-up period. However, our study had some limitations: autopsies were not performed on a number of infants who died, many diagnoses lacked specific laboratory analyses, and a number of infants were lost to follow-up. Nevertheless, while the lack of specific testing and the loss of almost half the infants with associated clefts might affect the proportions of specific diagnoses, they do not affect the overall rate of associated clefts. On the other hand, the loss of one-third of the infants with apparently isolated clefts precludes an accurate estimate of the actual prevalence of associated clefts. In large urban areas of developing countries, community medical programs outside the hospital face serious challenges due to such problems as unstable families, frequent changes of residence, and the absence of official registries, all of which make patientś follow-up difficult even for short periods of time.

Notwithstanding the loss of a significant number of infants, it was possible to demonstrate that at least $7 \%$ of those initially diagnosed as having an isolated cleft had other significant defects. This minimum rose to $9 \%$ after including the ten newborns with isolated clefts who had a syndrome detectable only through laboratory findings or family history. Furthermore, 
less than $10 \%$ of the infants without a complete one-year follow-up were lost during the first month of life, a time when the most severe defects are usually diagnosed.

Since ECLAMC is a hospital-based program, it does not serve as a source for population rates of clefts and associated conditions. Most ECLAMC hospitals are referral centers for pregnancies with prenatally detected fetal anomalies and, consequently, their rates of associated defects diagnosed at birth are probably higher than the population rates. However, there is no reason to assume that the population rates of anomalies potentially detectable at older ages are different from the minimum value observed here.

One strength of this study was that within the ECLAMC network, birth defects in newborn infants are ascertained by pediatricians following a common methodology and strictly defined operating procedures, thus ensuring reliable and homogeneous data. Furthermore, as this was a prospective study in which the primary aim was to evaluate outcomes at different ages, it used a strictly defined protocol in addition to the previously described routine procedures, and was also free of such well-known limitations as incomplete records or recall biases that are common in retrospectively obtained data.

\section{Birth prevalence estikmates of cleft types}

The highest birth prevalence estimate was found for CLP, followed by CP and CLO. Most authors have found a similar predominance of CLP while their rates of CP vary, a fact which might be explained by methodological differences, such as referral sources and ages of the patients [Wyszynski et al., 2006]. Shprintzen et al. [1985], for instance, observed the highest rates for $\mathrm{CP}$, but many of their patients were older and it was thus possible to detect less conspicuous types of cleft, such as submucous $\mathrm{CP}$, which in fact represented $43 \%$ of their $\mathrm{CP}$ cases.

The lowest rates have been found for CLO by most authors who evaluated CLO and CLP separately [Owens et al., 1985; Jensen et al., 1988; Harville et al., 2005; Calzolari et al., 2007; Genisca et al., 2009]. Barbosa et al. [2003] observed slightly lower CP than CLO rates, but their patients were from multiple referral sources and of different ages. Rajabian and Sherkat [2000] reported an excess of CLO in a sample of patients who belonged to a population with high consanguinity rates. Harville et al. [2005] suggested that children of consanguineous parents are at a greater risk for CLO than for CLP, and their results suggest a greater genetic component in the etiology of CLO than in that of CLP.

In the present study, the small sample size only allows us to suggest that CLO was more frequent among those infants who died (36\%) than among the total group with isolated clefts (21\%), and that the mortality rate was higher among infants with CLO than among those with other types of cleft.

\section{Proportions of associated defects}

Reported prevalence estimates of associated defects in patients with clefts are even more variable, ranging from about $8 \%$ [Rajabian and Sherkat, 2000] to 75\% in a sample of prenatally diagnosed fetuses [Lopoo et al., 1999], and again, much of this variation could reflect methodological differences. For example, Shprintzen et al. [1985] reported that up to $63 \%$ of their patients had associated clefts, a finding which was probably due to their definition of associated anomalies. They considered a cleft as associated even if only minor defects or facial features often observed with clefts, such as ocular hypertelorism or a hypoplastic nose, were present. Similarly, the high prevalence of associated anomalies reported by Shaw et al. [2004] (71.1\% for CP and 59.8\% for CL with or without CP), could be due, at least partially, to the inclusion of minor defects. In the present study, a cleft was defined as associated only when major structural defects or syndromes, identified or strongly 
suspected, were present. The observed $31 \%$ of associated defects is similar to the $29 \%$ reported by Shafi et al. [2003] and by Calzolari et al. [2007], and probably higher than the $21 \%$ reported by Milerad et al. [1997], but again, all these studies show methodological differences that hinder a reliable comparison.

CP had the highest prevalence of associated defects, and CLO the lowest. Similar distributions have been observed by Fraser and Calnan [1961], Stoll et al. [2000], and Rawashdeh and Jawdat [2008], among others, while Milerad et al. [1997] reported the highest prevalence for CLP, followed by CP and CLO. The lowest prevalence of associated defects has been found for CLO by all authors analyzing CLP and CLO separately [Milerad et al., 1997; Tolarova and Cervenka, 1998; Stoll et al., 2000; Harville et al., 2005; Genisca et al., 2009].

\section{Diagnoses in associated cases}

Chromosomal abnormality syndromes were slightly more frequent than syndromes without chromosomal abnormalities. Conditions with arthrogryposis predominated among the latter, with $\mathrm{CP}$ as the most frequent type of cleft. This finding was also reported by Rittler et al. [2008] in a sample partially overlapping that of the present study. CP is often found in conditions with fetal akinesia, possibly as a consequence of joint immobility during fetal development [Bannigan and Cottell, 1991].

The most frequent malformation complex or sequence found in our sample of infants with clefts was the branchial arch complex. Although oral clefts are usually not considered as diagnostic criteria for the branchial arch "syndrome" (which includes oculoauriculovertebral syndrome and hemifacial microsomia), they are present in a remarkably high number of cases in most reviews on branchial arch anomaly conditions [Rollnick et al, 1987; Gorlin et al., 1990]. The coexistence of ear defects and oral clefts has been described in over 100 syndromes, such as Treacher Collins-Franceschetti, CHARGE, branchiootorenal, Nager, and Marden-Walker, among others [Baraitser and Winter, 2001]. Rittler et al. [2008] found a significant association between CLO and severe ear anomalies, while in the study of Rollnick et al. [1987], CP was the type of cleft most frequently associated with ear defects, but different sample sources might explain these discordant findings.

Facial morphogenesis is the consequence of complex interacting processes. Different mechanisms predominate in the development of the external ear and in that of the upper lip and palate. Mesenchymal underdevelopment of first and second branchial arches, due to a reduced neural crest migration, can account for external ear malformations while an impaired or delayed fusion of maxillary and nasal processes, or palatal shelves, leads to a cleft lip or palate [Farlie et al., 2004; Greene and Pisano, 2010]. However, the preferential association between ear anomalies and oral clefts suggests that in a certain number of cases, a specific factor acting through a different pathway, or more extensive damage to the first and second branchial arches, might be involved. The fact that regions of high altitude constitute a significant risk factor for both oral clefts and microtia [Castilla and Orioli, 1986; Castilla et al., 1999] provides further evidence supporting this hypothesis.

Three other complexes/sequences were observed: anencephaly, amniotic bands sequence, and holoprosencephaly. In anencephalic infants, a cleft palate can be expected, due to the grossly disorganized skull base, and similarly, Shaw et al. [2004] reported a prevalence of $\mathrm{CP}$ fifty times higher in anencephalic infants than in the overall population.

For the recognized association between clefts and amniotic bands, a number of theories [Streeter, 1930; Torpin, 1965; Van Allen et al., 1987a) have been proposed although none has been universally accepted. 
In most patients with holoprosencephaly, the coexisting cleft is midline and this type was not included in the study. Furthermore, holoprosencephaly is often part of a syndrome or shows other associated defects [Baraitser and Winter, 2001]. As expected, only one holoprosencephalic infant with a non-midline cleft lip and without other associated anomalies was identified.

The largest group of associated clefts was that of MCAs, and CHDs were the most frequently associated defects, in agreement with Shafi et al. [2003], Rawashdeh and Jawdat [2008], and Genisca et al., [2009], among others. Milerad et al. [1997] reported that limb and vertebral column anomalies were the defects that most often coexisted with clefts but only in infants with more than two anomalies, while CHDs predominated when present as the only associated defect.

In our study, however, the proportion of infants with clefts and CHDs did not differ from the proportion of infants with CHDs and other non-cleft anomalies ascertained in the same hospitals. Furthermore, Rittler et al. [2008] found a significantly negative association between CHDs and clefts when compared with the association between CHDs and non-cleft anomalies, and Shaw et al. [2004] observed low relative risks for CHDs in infants with clefts when compared to the risks for CHDs in infants with other non-cleft anomalies. All these results could indicate that the association between CHDs and any other defect including clefts is frequent yet nonspecific.

The present results, which are similar to those of Rawashdeh and Jawdat [2008], show that CP was the type of cleft most often associated with CHDs. For Liang et al. [1999] the most frequent type was CLP, and Barbosa et al. [2003] found no correlation between CHDs and cleft type, but this finding might have been the consequence of their already mentioned lower CP rates.

\section{Isolated/associated versus non-syndromic/syndromic}

In ten infants with isolated clefts in whom other major defects were neither detected nor suspected during the one-year follow-up period, a syndrome could only be diagnosed through laboratory findings or family history. This illustrates the difference between the terms isolated/associated and non-syndromic/syndromic. While the first two refer to the number of defects, regardless of the cause or the mechanisms involved, the terms syndromic/non-syndromic refer not to the number of defects but rather to the underlying common cause that leads to the observed single or multiple anomalies [Benirschke et al., 1979; Spranger et al., 1982]. However, both terms are often used interchangeably [Tan et al., 2009], mostly in the recent molecular genetics literature [Mitchell et al., 2003; Carinci et al., 2007; Song et al., 2008]. For a better understanding and interpretation of descriptions and results, it seems advisable to use the terms associated/isolated when referring to the presence or absence of associated defects, and to use the terms syndromic/non-syndromic when referring to etiology.

\section{Follow-up}

The finding that at least $7 \%$ of infants initially diagnosed as having isolated clefts actually had other associated anomalies reflects the facts that certain birth defects are not recognizable at birth and that the prevalence of diagnosed syndromes and other associated anomalies increases with age.

Shprintzen et al. [1985] concluded that the higher prevalence of associated anomalies in older patients when compared to younger patients with clefts was due to the fact that a submucous cleft palate (which is obviously diagnosed at older ages) associates more frequently with other defects than an overt cleft palate. It seems more likely, however, that 
both the submucous cleft and the associated anomalies (which were not clearly specified) reveal themselves independently of each other at older ages.

In the present study, most of the syndromes that were not initially diagnosed were identified between 7 and 28 days of life and the slight variations depended on the syndrome itself as well as on the pediatriciańs ability to recognize it. Most of the other major anomalies were also diagnosed during the first month of life. CHDs were diagnosed at different ages up to a maximum of nine months (a patent ductus arteriosus that failed to close). This finding enhances on the one hand the role of follow-up in the more accurate identification of certain birth defects and syndromes. On the other hand, it allows for adjustments in the rates of birth defects in newborns without follow-up. Even short periods of time, such as one week, can be long enough to lead to an underestimation of associated anomalies. Nevertheless, and in view of the decreasing detection of additional anomalies after the first month of life, the number of associated defects that still remain undiagnosed after the first year, as well as their severity, is probably low.

Our finding that at least $7 \%$ of infants with apparently isolated clefts in fact have associated clefts, and that this minimum reaches $9 \%$ when infants with isolated clefts and unsuspected underlying syndromes are included, should be taken into account when newborns without follow-up are enrolled in studies on the etiology of non-syndromic oral clefts.

\section{Acknowledgments}

Norman Goco, Lorette Javois and many colleagues at RTI, Mariana Piola and Alejandra Mariona of the Eclamc staff, facilitated data collection and training. The authors are especially grateful to the families for their participation and they wish to thank the following physicians of the ECLAMC network who provided assessment and data base entry with precision and managed the infants and families with care and passion: Nazer Herrera J, Catalán R, Hospital Clínico de la Universidad de Chile, Santiago, Chile; Ojeda ME, Hospital Regional de Rancagua, Rancagua, Chile; Canessa A, Hospital Base Pediatría, Linares, Chile; Wettig E, Hospital Base de Puerto Montt, Puerto Montt, Chile; Fontannaz AM, Villagrán J, Smith J, Mellado C, Hospital Sótero del Río, Santiago, Chile; Farfán V, Hospital Regional de Talca, Talca, Chile; Rittler M, Hospital Ramón Sardá, Buenos Aires, Argentina; Persini C, Rottenberg D, Hospital Francisco Santojanni, Buenos Aires, Argentina; Cosentino V, Hospital Luisa C. de Gandulfo, Lomas de Zamora, Buenos Aires, Argentina; Jewtuszyk M, Hospital Narciso López, Lanús Este, Buenos Aires, Argentina; Lerner M, Hospital Centenario de Gualeguaychú, Entre Rios, Argentina; Mussi M, Maternidad Martín, Rosario, Santa Fé, Argentina; Ermini M, Hospital Italiano, La Plata, Buenos Aires, Argentina; Deguer C, Hospital Interzonal de Agudos Dr. José Penna, Bahía Blanca, Buenos Aires, Argentina; Cárpena L, Hospital Nuestra Sra. de la Misericordia, Córdoba Argentina; Chirino A, Clínica Concepción SRL, Córdoba, Argentina; Echegaray A, Hospital Materno Neonatal, Córdoba, Argentina; Negri C, Hospital Regional Alfredo Parpato, San Martín, Mendoza, Argentina; Menzio M, Hospital de San Luis, San Luis, Argentina; Saleme C, Maternidad Nuestra Sra. de la Merced, San Miguel de Tucumán, Tucumán, Argentina; Lombardelli R, Hospital Zonal de Esquel, Chubut, Argentina; Mereb JC, Hospital de Area de El Bolsón, Río Negro, Argentina; Nogueira A, Maternidad Carmela Dutra, Florianópolis, Brasil; Canonaco R, Hospital dos Servidores do Estado, Sao Paulo, Brasil; Leite JC, Hospital de Clínicas de Porto Alegre, Porto Alegre, Brasil; Cavalcanti D, Hospital CAISM, Campinas, Brasil; Ternes Pereira E, Hospital Universitario UFSC, Florianópolis,Brasil; Abath C, Maternidad Candida Vargas, Joao Pessoa, Brasil; Rueda S, Maternidad Natalio Aramayo and Hospital San Gabriel, La Paz, Bolivia; Montalvo G, Maternidad Andrade Marín, Quito, Ecuador; Toscano M, Hospital Dr. Napoleón Dávila Córdova, Manabi, Ecuador; Martínez E, Hospital Luis F Martínez, Cañar, Ecuador and Hospital Homero Castanier, Azogues, Ecuador; Sacoto A, Maternidad Fundación Mano Amiga, Cañar, Ecuador; Girón C, Hospital Verdi Cevallos Balda, Manabi, Ecuador; Camacho A, Hospital San Vicente, Clínica La Inmaculada, Ibarra, Ecuador; Cedeño R, Maternidad Castillo Plaza, Maracaibo, Venezuela; Jatar B, Hospital Gral. Dr. Alfredo Van Grieken, Coro, Venezuela; Zarante I, Hospital Universitario San Ignacio and Fundación Clínica Emmanuel, Bogotá, Colombia; Durán M, Clínica David Restrepo, Bogotá, Colombia; Villegas CA, Hospital de Caldas, Caldas, Colombia and Clínica Villa Pilar, Manizales, Colombia; Luna Ballén AM, Hospital Pedro León Alvarez Díaz, La Mesa, Colombia; Cristancho C, Hospital El Salvador, Ubaté, Colombia.

Grant sponsor: CONICET PEI, Argentina; Grant number: 6475-2007-2008; Grant sponsor: MCT/CNPq, Brazil; Grant numbers 573993/2008-4, 476978/2008-4, and 308885/2006-6, NIH U01 HD-40561 and R01DE08559. 


\section{REFERENCES}

Bannigan JG, Cottell DC. Development of the lung in mice with bromodeoxyuridine-induced cleft palate. Teratology. 1991; 44:165-176. [PubMed: 1925975]

Baraitser, M.; Winter, RM. London Dysmorphology Database, London Neurogenetics Database, and Dysmorphology Photo Library. 3rd ed. Oxford University Press; Oxford: 2001.

Barbosa MM, Rocha CM, Katina T, Caldas M, Codorniz A, Medeiros C. Prevalence of congenital heart diseases in oral cleft patients. Pediatr Cardiol. 2003; 24:369-374. [PubMed: 12522651]

Benirschke K, Lowry RB, Opitz JM, Schwarzacher HG, Spranger JW. Developmental terms-some proposals: first report of an international working group. Am J Med Genet. 1979; 3:297-302. [PubMed: 484597]

Bower C, Rudy E, Callaghan A, Quick J, Nassar N. Age at diagnosis of birth defects. Birth Defects Res A Clin Mol Teratol. 2010; 88:251-255. [PubMed: 20213697]

Calzolari E, Pierini A, Astolfi G, Bianchi F, Neville AJ, Rivieri F. Associated anomalies in multimalformed infants with cleft lip and palate: An epidemiologic study of nearly 6 million births in 23 EUROCAT registries. Am J Med Genet A. 2007; 143:528-537. [PubMed: 17286264]

Carinci F, Scapoli L, Palmieri A, Zollino I, Pezzetti F. Human genetic factors in nonsyndromic cleft lip and palate: an update. Int J Pediatr Otorhinolaryngol. 2007; 71:1509-1519. [PubMed: 17606301]

Castilla EE, Orioli IM. Prevalence rates of microtia in South-America. Int J Epidemiol. 1986; 15:364368. [PubMed: 3771073]

Castilla EE, Lopez-Camelo JS, Campaña H. The Altitude as a Risk Factor for Congenital Anomalies. Am J Med Genet. 1999; 86:9-14. [PubMed: 10440822]

Castilla EE, Orioli IM. ECLAMC: The Latin American Collaborative Study of Congenital Malformations. Community Genetics. 2004; 7:76-94. [PubMed: 15539822]

Castilla E, Orioli M. Classification system for cleft lip and palate. Cleft Palate Craniofac J. 2009; 46:220. [PubMed: 19254063]

Farlie PG, McKeown SJ, Newgreen DF. The neural crest: basic biology and clinical relationships in the craniofacial and enteric nervous systems. Birth Defects Res C Embryo Today: Reviews. 2004; 72:173-189.

Fraser GR, Calnan JS. Cleft lip and palate: seasonal incidence, birth weight, birth rank, sex, site, associated malformations and parental age. A statistical survey. Arch Dis Child. 1961; 36:420423. [PubMed: 13701506]

Genisca AE, Frías JL, Broussard CS, Honein MA, Lammer EJ, Moore CA, Shaw GM, Murray JC, Yang W, Rasmussen SA, National Birth Defects Prevention Study. Orofacial clefts in the National Birth Defects Prevention Study, 1997-2004. Am J Med Genet A. 2009; 149A:1149-1158. [PubMed: 19441124]

Gorlin, RJ.; Cohen, MM.; Levin, LS. Syndromes of the head and neck. 3rd ed. Oxford University Press; Oxford: 1990. Branchial arch and oro-acral disorders; p. 641-691.

Greene RM, Pisano MM. Palate Morphogenesis: current understanding and future directions. Births Defects Res C Embryo Today: Reviews. 2010; 90:133-154.

Harville EW, Wilcox AJ, Lie RT, Vindeness H, Abyholm F. Cleft lip and palate versus cleft lip only: are they distinct defects? Am J Epidemiol. 2005; 162:448-453. [PubMed: 16076837]

ICBDSR: International Centre for Birth Defects Surveillance and Research. Annual Report 2007. 2009. http://www.icbdsr.org

Jensen BL, Kreiborg S, Dahl E, Fogh-Andersen P. Cleft lip and palate in Denmark, 1976-1981: epidemiology, variability, and early somatic development. Cleft Palate J. 1988; 25:258-269. [PubMed: 3262457]

Liang CD, Huang SC, Lai JP. A survey of congenital heart disease in patients with oral clefts. Acta Paediatr Taiwan. 1999; 40:414-417. [PubMed: 10927955]

Lopoo JB, Hedrick MH, Chasen S, Montgomery L, Chervenak FA, Goldstein R, Hoffman WY, Harrison MR, Longaker MT. Natural history of fetuses with cleft lip. Plast Reconstr Surg. 1999; 103:34-38. [PubMed: 9915161]

Milerad J, Larson O, Hagberg C, Ideberg M. Associated malformations in infants with cleft lip and palate: a prospective, population-based study. Pediatrics. 1997; 100:180-186. [PubMed: 9240796] 
Mitchell LE, Murray JC, O’Brien S, Christensen K. Retinoic acid receptor alpha gene variants, multivitamin use, and liver intake as risk factors for oral clefts: a population-based case-control study in Denmark, 1991-1994. Am J Epidemiol. 2003; 158:69-76. [PubMed: 12835288]

Owens JR, Jones JW, Harris F. Epidemiology of facial clefting. Arch Dis Child. 1985; 60:521-524. [PubMed: 4040354]

Rajabian MH, Sherkat M. An epidemiologic study of oral clefts in Iran: analysis of 1,669 cases. Cleft Palate Craniofac J. 2000; 37:191-196. [PubMed: 10749061]

Rawashdeh MA, Jawdat Abu-Hawas B. Congenital associated malformations in a sample of Jordanian patients with cleft lip and palate. J Oral Maxillofac Surg. 2008; 66:2035-2041. [PubMed: 18848099]

Rittler M, Lopez-Camelo JS, Castilla EE, Bermejo E, Cocchi G, Correa A, Csaky-Szunyogh M, Danderfer R, De Vigan C, De Walle H, Dutra MG, Hirahara F, Martínez-Frías ML, Merlob P, Mutchinick O, Ritvanen A, Robert-Gnansia E, Scarano G, Siffel C, Stoll C, Mastroiacovo P. Preferential Associations Between Oral Clefts and Other Major Congenital Anomalies. Cleft Palate Craniofac J. 2008; 45:525-532. [PubMed: 18788868]

Rollnick BR, Kaye CI, Nagatoshi K, Hauck W, Martin AO. Oculoauriculovertebral dysplasia and variants: phenotypic characteristics of 294 patients. Am J Med Genet. 1987; 26:361-375. [PubMed: 3812588]

Shafi T, Khan MR, Atiq M. Congenital heart disease and associated malformations in children with cleft lip and palate in Pakistan. Br J Plast Surg. 2003; 56:106-109. [PubMed: 12791351]

Shaw GM, Carmichael SL, Yang W, Harris JA, Lammer EJ. Congenital malformations in births with orofacial clefts among 3.6 million California births, 1983-1997. Am J Med Genet. 2004; 125A: 250-256. [PubMed: 14994232]

Shprintzen RJ, Siegel-Sadewitz VL, Amato J, Goldberg RB. Anomalies associated with cleft lip, cleft palate, or both. Am J Med Genet. 1985; 20:585-595. [PubMed: 3993684]

Song T, Li G, Jing G, Jiao X, Shi J, Zhang B, Wang L, Ye X, Cao F. SUMO1 polymorphisms are associated with non-syndromic cleft lip with or without cleft palate. Biochem Biophys Res Commun. 2008; 377:1265-1268. [PubMed: 18983974]

Spranger J, Benirschke K, Hall JG, Lenz W, Lowry RB, Opitz JM, Pinsky L, Schwarzacher HG, Smith DW. Errors of morphogenesis: concepts and terms. J Pediatr. 1982; 100:160-165. [PubMed: 7057306]

Stoll C, Alembik Y, Dott B, Roth MP. Associated malformations in cases with oral clefts. Cleft Palate Craniofac J. 2000; 37:41-47. [PubMed: 10670888]

Streeter GL. Focal deficiencies in fetal tissues and their relation in intrauterine amputations. Contrib Embryol Carnegie Inst. 1930; 22:1-46.

Tan TY, Amor DJ, Riley M, Halliday J, Kilpatrick N, Simms K, White SM. Registry- and clinic-based analyses of birth defects and syndromes associated with cleft lip/palate in Victoria, Australia. Cleft Palate Craniofac J. 2009; 46:583-587. [PubMed: 19929084]

Tolarova MM, Cervenka J. Classification and birth prevalence of orofacial clefts. Am J Med Genet. 1998; 75:126-137. [PubMed: 9450872]

Torpin R. Amniochorionic mesoblastic fibrous strings and amniotic bands. Am J Obstet Gynec. 1965; 91:65-75. [PubMed: 14245093]

Van Allen MI, Curry C, Gallagher L. Limb body wall complex: I. Pathogenesis. Am J Med Genet. 1987a; 28:529-548. [PubMed: 2962493]

Wehby GL, Castilla EE, Goco N, Rittler M, Cosentino V, Javois L, McCarthy AM, Bobashev G, Litavecz S, Mariona A, Dutra G, Lopez-Camelo JS, Orioli IM, Murray JC. Description of the methodology used in an ongoing pediatric care interventional study of children born with cleft lip and palate in South America. BMC Pediatr. 2006; 6:1-29. [PubMed: 16457711]

Wyszynski DF, Sárközi A, Czeizel AE. Oral clefts with associated anomalies: methodological issues. Cleft Palate Craniofac J. 2006; 43:1-6. [PubMed: 16405364] 


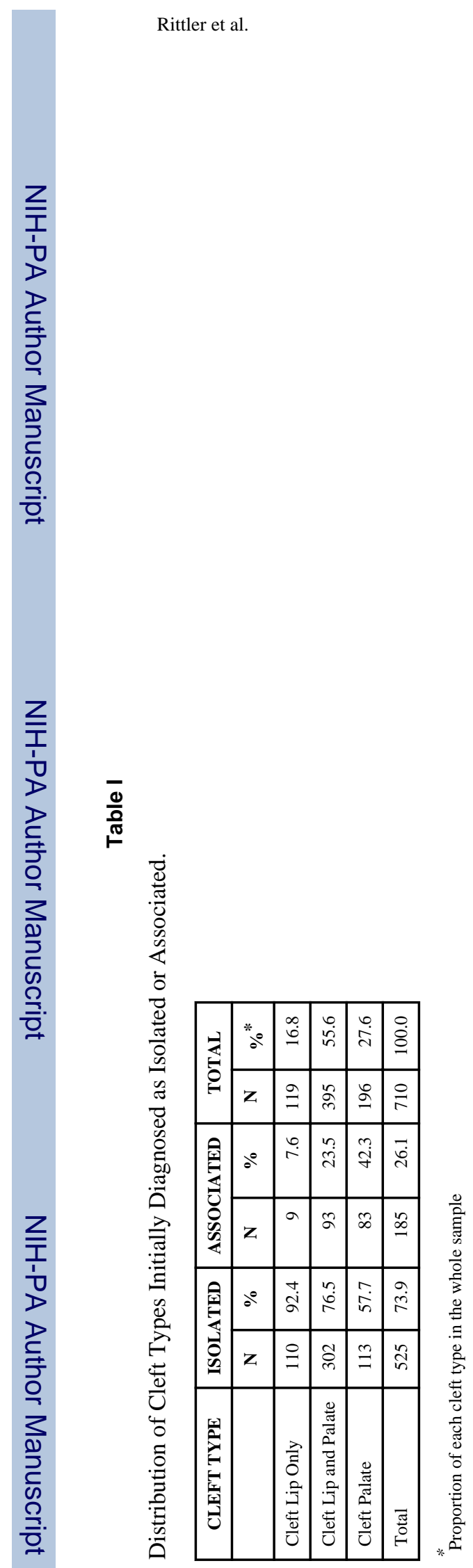

Page 12

Am J Med Genet A. Author manuscript; available in PMC 2013 May 10. 
0
0
0
0
0
0
0
0
0
0
0
0
0
0
0 

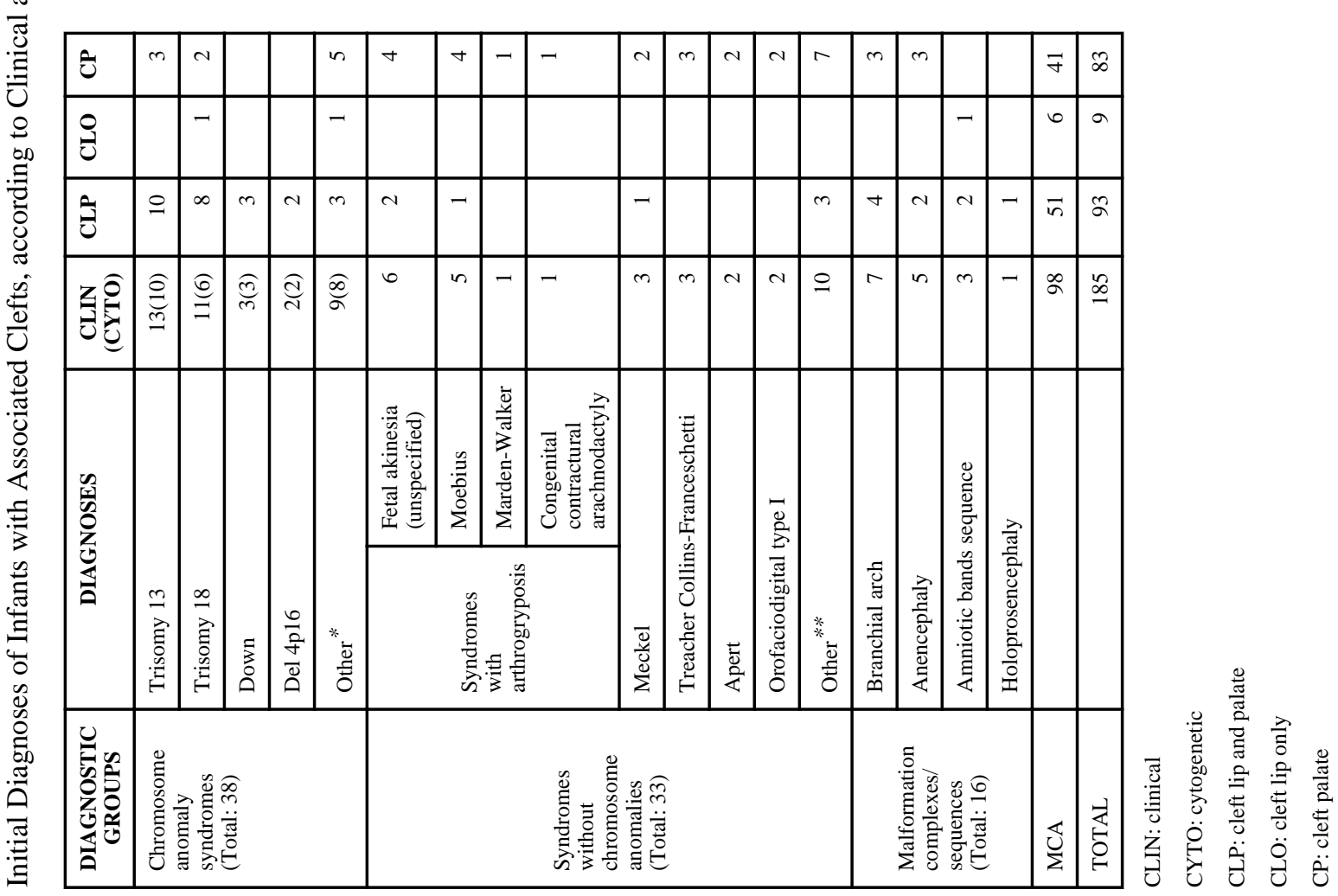




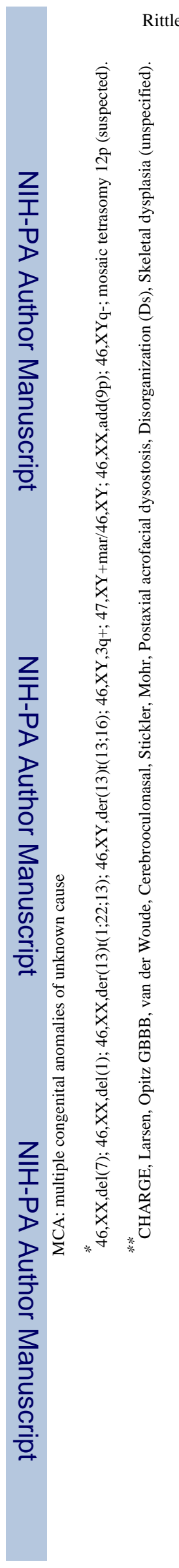


Table III

Reasons for Reassignment of 38 Infants with Isolated Clefts to the Associated Clefts Group, and Final Diagnoses.

\begin{tabular}{|c|c|}
\hline Reason for reassignment and final diagnoses & $\mathbf{N}$ \\
\hline 1. Detection of major defects $(\mathrm{N}=24)$ & \\
\hline Syndromes & 5 \\
\hline MCA & 19 \\
\hline 2. Re-evaluation of minor anomalies ( $\mathrm{N}=8)$ & \\
\hline Chromosomal abnormality & 6 \\
\hline Rubinstein-Taybi syndrome & 1 \\
\hline Cornelia de Lange syndrome & 1 \\
\hline 3. Wrong assignment at birth (N=6) & \\
\hline Chromosomal abnormality & 3 \\
\hline Hydrops fetalis & 1 \\
\hline Lethal skeletal dysplasia & 1 \\
\hline MCA & 1 \\
\hline Total & 38 \\
\hline
\end{tabular}

MCA: multiple congenital anomalies of unknown cause 


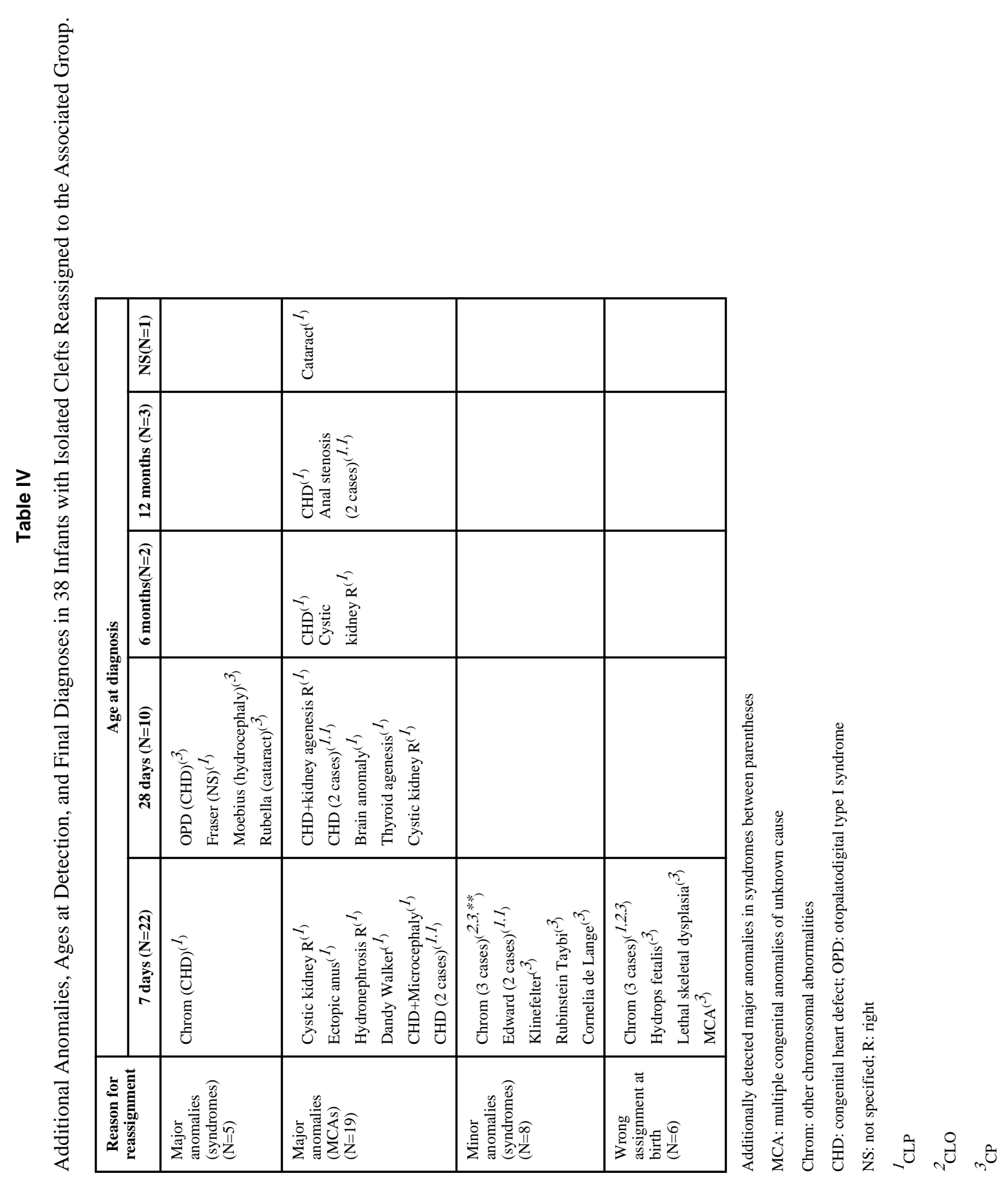


Table V

Syndromes Diagnosed through Laboratory Findings or Family History in 10 Infants with Isolated Clefts.

\begin{tabular}{|c|c|c|}
\hline $\begin{array}{l}\text { DIAGNOSTIC } \\
\text { EVIDENCE }\end{array}$ & SYNDROME & $\underset{\mathbf{N}}{\operatorname{CASES}}$ \\
\hline CGH & del 22q11.2 $2^{(1,2,3)}$ & 3 \\
\hline Mutation analysis & $\begin{array}{l}\text { van der Woude }(1,1) \\
\text { Kallmann }(1)\end{array}$ & $\begin{array}{l}2 \\
1\end{array}$ \\
\hline Cytogenetics & $\begin{array}{l}46, \mathrm{X}, \operatorname{del}(\mathrm{X})(\mathrm{q} 1.3)^{\left(1_{1}\right)} \\
46, \mathrm{XY}, \operatorname{add}(15)(\mathrm{p} 11)^{(1)}\end{array}$ & $\begin{array}{l}1 \\
1\end{array}$ \\
\hline Family history & $\begin{array}{l}\text { Sib with Stickler syndrome }{ }^{(3)} \\
\text { Twin sib with holoprosencephaly }\left({ }^{2}\right)\end{array}$ & $\begin{array}{l}1 \\
1\end{array}$ \\
\hline TOTAL & & 10 \\
\hline
\end{tabular}

CGH: Comparative genomic hybridization

${ }^{1} \mathrm{CLP}$

$2_{\mathrm{CLO}}$

${ }^{3} \mathrm{CP}$ 